\title{
Advanced Control for Electric Drives: Current Challenges and Future Perspectives
}

\author{
Adel Merabet ${ }^{(1)}$ \\ Division of Engineering, Saint Mary's University, Halifax, NS B3H 3C3, Canada; \\ adel.merabet@smu.ca; Tel.: +1-902-420-5712
}

Received: 2 October 2020; Accepted: 21 October 2020; Published: 23 October 2020

\begin{abstract}
In the Special Issue "Advanced Control for Electric Drives", the objective is to address a variety of issues related to advances in control techniques for electric drives, implementation challenges, and applications in emerging fields such as electric vehicles, unmanned aerial vehicles, maglev trains and motion applications. This issue includes 15 selected and peer-reviewed articles discussing a wide range of topics, where intelligent control, estimation and observation schemes were applied to electric drives for various applications. Different drives were studied such as induction motors, permanent magnet synchronous motors and brushless direct current motors.
\end{abstract}

Keywords: motor drives; advanced control; power converters; estimation; sensor; artificial intelligence

\section{Introduction}

In recent years, electric drives have attracted the attention of researchers in emerging fields such as electric vehicles (EV), renewable energy systems (wind, tidal, ocean, etc.) and high precision motion applications [1-3]. Electric drives are composed of electrical machines, power electronic converters and control systems. Their efficient operation, for position and speed regulation, is determined by the control system. Furthermore, electric drives are a highly nonlinear, multivariable, time-varying system, depending on the type of the electrical machine, and require more complex methods of control. Therefore, they constitute a theoretical and practical challenge in control, estimation and efficient operation in different applications [4-7].

\section{The Special Issue}

This Special Issue covers a wide range of topics in the field of electric drives. It contains 15 articles studying advanced control schemes, estimation, disturbance rejection and energy management in different applications of electric drives. This section summarizes the content of these articles.

In [8], a predictive controller was developed for tracking a reference current provided by the speed control loop in permanent magnet synchronous motors (PMSM). The control scheme includes a disturbance observer, based on an equivalent input-disturbance approach combined with the deadbeat predictive controller, to improve its robustness. The provided results demonstrate that the proposed control method, compared to the conventional proportional-integral (PI) control, offers smaller fluctuation and shorter settling time for the starting current of the motor. In [9], the bird swarm algorithm, a bio-inspired evaluation approach, was improved and implemented to develop an energy management of extended-range electric vehicles. In this optimization technique, the spatial distance from the center of the bird swarm, instead of fitness function value, was used to stand for their intimacy of relationship. In [10], a multi-sensor data fusion method was developed to detect a safe distance between the unmanned aerial vehicle (UAV) and the transmission lines. This approach takes into consideration the physical model of the UAV in the complex electromagnetic field and the main factors affecting the UAV to develop an adaptive weighted fusion algorithm to conduct analysis 
on the sensor data. In [11], a cascade second order sliding mode control (SMC) scheme was applied to a PMSM for speed and current control loops. This SMC technique includes an integral action and takes into consideration the nonlinear dynamics and uncertainties. The control robustness, against parametric variations, external disturbance and unknown load, was improved using this control scheme. Another predictive control technique for PMSM current was proposed in [12]. The method uses a two-step-ahead prediction to compensate the delay between the measurements and actuation that causes current ripples. Furthermore, the deadbeat principle and the inverse model of PMSM were used to obtain the reference stator voltage, and an identification system was developed to deal with parametric inaccuracies of the predictive model. In [13], an adaptive SMC scheme was proposed to obtain the desired torque trajectory of the clutch transmission in the mode transition of single-shaft parallel hybrid electric vehicles. Furthermore, a proportional-integral (PI) observer was designed to estimate the actual transmission torque of the clutch. Finally, a fractional order proportional-integral-differential (FOPID) controller, with optimized control parameters by particle swarm optimization (PSO), was employed to realize the accurate position tracking of the direct current (DC) motor clutch required to ensure clutch transmission torque tracking. In [14], an efficient proportional derivative (PD) position controller was developed for three-phase motor drives. The effect of the load disturbance was compensated by a feed forward term. The proposed method was validated on the two different drives (induction motor, PMSM) and demonstrated good performance with respect to parametric uncertainties, unknown load disturbance and measurement noise in the position and current loops. In [15], an estimator and an intelligent controller were proposed for sensorless control of the PMSM drive. The estimator, for position and rotor speed estimation, was constructed using a sliding mode observer and a phase-locked loop. The intelligent controller was used for the velocity control loop. This includes a radial basis function neural network (RBFNN) for self-tuning of the proportional-integral-derivative (PID) controller. In [16], a low-order finite impulse response (FIR) filter, for a high-frequency signal injection method in the permanent magnet linear synchronous motor (PMLSM), was designed for position observation. The filter coefficients were obtained using constraint equations based on the amplitude-frequency characteristics of the FIR filter. In [17], state-of-the art position sensor technologies were investigated for use in PMSM drives applied to automotive electric powertrain systems. Multiple sensor systems were analyzed based on different influencing factors and performance indicators in the automotive field. In [18], the speed control for brushless direct current (BLDC) motors, in steel rolling applications, was investigated using a cascade control loop. The load torque and the speed reference were calculated from the rolling process. In [19], the influence of the harmonic torque on the performance of PMSM drive, in a pure electric vehicle, was investigated by considering the dead-time, the voltage drop effects and the nonlinear characteristics of the transmission system. In [20], a feedback controller was designed for controlling a three-phase linear induction motor. The system modeling was carried out using a neural network identifier to deal with uncertainties due to disturbances, unmodeled quantities, sensors and actuators. In [21], a fuzzy logic control was used for speed tracking in PMSM drives. The intelligent controller was adjusted by a radial basis function neural network. Furthermore, sensorless control was granted by a sliding mode observer for the rotor position and the speed estimation. In [22], the SMC method was combined with a fractional order synergetic technique for speed and current control to deal with nonlinearities and uncertainties. Furthermore, a sliding mode observer was used to estimate the rotor position and speed, based on the motor voltages and currents, for sensorless operation. In order to ensure the high performance of the sensorless control system, a fault detection system was implemented for the current sensors.

\section{Future Perspectives}

The use of electric drives in sophisticated systems, such as electric and unmanned vehicles, renewable energy systems and robots, is growing with complicated motion and high precision requirements. Furthermore, the evolution and involvement of multi-phase electric machines and power converters require precise, fast and efficient control for the speed and the position, which cannot 
be achieved by conventional control systems. Smart control systems, which incorporate artificial intelligence tools, sensorless and wireless concepts, and data analysis for adaptive modeling, are emerging to enhance the operation of electric drives. Therefore, the research in this field will remain very active [23-26].

Funding: The guest editing of this Special Issue and publication of this editorial was funded by the Natural Sciences and Engineering Research Council of Canada (NSERC), discovery grant RGPIN-2018-05381.

Acknowledgments: The author would like to thank the editorial board of Electronics for the opportunity to serve as the Guest Editor of this Special Issue. Many thanks to all researchers who submitted articles to this Special Issue for their excellent contributions. Gratitude and thank you to all reviewers for their comments and suggestions to improve the quality of contributions. Finally, congratulations for the Electronics editorial office team for the success in managing this Special Issue.

Conflicts of Interest: The author declares no conflict of interest.

\section{References}

1. Shao, L.; Karci, A.E.H.; Tavernini, D.; Sorniotti, A.; Cheng, M. Design approaches and control strategies for energy-efficient electric machines for electric vehicles-A review. IEEE Access 2020, 8, 116900-116913. [CrossRef]

2. Nair, R.; Gopalaratnam, N. Emulation of wind turbine system using vector controlled induction motor drive. IEEE Trans. Ind. Appl. 2020, 56, 4124-4133. [CrossRef]

3. Khatri, P.; Wang, X. Comprehensive review of a linear electrical generator for ocean wave energy conversion. IET Renew. Power Gener. 2020, 14, 949-958. [CrossRef]

4. Salem, A.; Narimani, M. A review on multiphase drives for automotive traction applications. IEEE Trans. Transport. Electrif. 2019, 5, 1329-1348. [CrossRef]

5. Li, L.; Liu, Q. Research on IPMSM drive system control technology for electric vehicle energy consumption. IEEE Access 2019, 7, 186201-186210. [CrossRef]

6. Rafaq, M.S.; Jung, J.-W. A comprehensive review of state-of-the-art parameter estimation techniques for permanent magnet synchronous motors in wide speed range. IEEE Trans. Ind. Inform. 2020, 16, 4747-4758. [CrossRef]

7. Tanvir, A.A.; Merabet, A. Artificial neural network and Kalman filter for estimation and control in standalone induction generator wind energy DC microgrid. Energies 2020, 13, 1743. [CrossRef]

8. Liu, X.; Zhang, Q. Robust current predictive control-based equivalent input disturbance approach for PMSM drive. Electronics 2019, 8, 1034. [CrossRef]

9. Wu, D.; Feng, L. On-off control of range extender in extended-range electric vehicle using bird swarm intelligence. Electronics 2019, 8, 1223. [CrossRef]

10. Zhang, W.; Ning, Y.; Suo, C. A method based on multi-sensor data fusion for UAV safety distance diagnosis. Electronics 2019, 8, 1467. [CrossRef]

11. Merabet, A. Cascade second order sliding mode control for permanent magnet synchronous motor drive. Electronics 2019, 8, 1508. [CrossRef]

12. Tang, P.; Dai, Y.; Li, Z. Unified predictive current control of PMSMs with parameter uncertainty. Electronics 2019, 8, 1534. [CrossRef]

13. Ding, J.; Jiao, X. A novel control method of clutch during mode transition of single-shaft parallel hybrid electric vehicles. Electronics 2020, 9, 54. [CrossRef]

14. Alkorta, P.; Barambones, O.; Cortajarena, J.A.; Martija, I.; Maseda, F.J. Effective position control for a three-phase motor. Electronics 2020, 9, 241. [CrossRef]

15. Hoai, H.-K.; Chen, S.-C.; Than, H. Realization of the sensorless permanent magnet synchronous motor drive control system with an intelligent controller. Electronics 2020, 9, 365. [CrossRef]

16. Zhao, H.; Zhang, L.; Liu, J.; Cai, J.; Shen, L. Design of a low-order FIR filter for a high-frequency square-wave voltage injection method of the PMLSM used in maglev train. Electronics 2020, 9, 729. [CrossRef]

17. Datlinger, C.; Hirz, M. Benchmark of rotor position sensor technologies for application in automotive electric drive trains. Electronics 2020, 9, 1063. [CrossRef] 
18. Nandakumar, M.; Ramalingam, S.; Nallusamy, S.; Rangarajan, S.S. Hall-sensor-based position detection for quick reversal of speed control in a BLDC motor drive system for industrial applications. Electronics 2020, 9, 1149. [CrossRef]

19. Hu, J.; Yang, Y.; Jia, M.; Guan, Y.; Fu, C.; Liao, S. Research on harmonic torque reduction strategy for integrated electric drive System in pure electric vehicle. Electronics 2020, 9, 1241. [CrossRef]

20. Alanis, A.Y.; Rios, J.D.; Gomez-Avila, J. Discrete-time neural control of quantized nonlinear systems with delays: Applied to a three-phase linear induction motor. Electronics 2020, 9, 1274. [CrossRef]

21. Hoai, H.-K.; Chen, S.-C.; Chang, C.-F. Realization of the neural fuzzy controller for the sensorless PMSM drive control system. Electronics 2020, 9, 1371. [CrossRef]

22. Nicola, M.; Nicola, C. Sensorless fractional order control of PMSM based on synergetic and sliding mode controllers. Electronics 2020, 9, 1494. [CrossRef]

23. Liu, D.; Song, X.; Deng, F.; Dong, J. Investigation into multi-phase armature windings for high-temperature superconducting wind turbine generators. IEEE Trans. Appl. Supercond. 2020, 30, 5201005. [CrossRef]

24. Bakir, H.; Merabet, A.; Dhar, R.K.; Kulaksiz, A.A. Bacteria foraging optimisation algorithm based optimal control for doubly-fed induction generator wind energy system. IET Renew. Power Gener. 2020, 14, 1850-1859. [CrossRef]

25. Schenke, M.; Kirchgässner, W.; Wallscheid, O. Controller design for electrical drives by deep reinforcement learning: A proof of concept. IEEE Trans. Ind. Inform. 2020, 16, 4650-4658. [CrossRef]

26. El-Sousy, F.F.M.; Abuhasel, K.A. Nonlinear robust optimal control via adaptive dynamic programming of permanent-magnet linear synchronous motor drive for uncertain two-axis motion control system. IEEE Trans. Ind. Appl. 2020, 56, 1940-1952. [CrossRef]

Publisher's Note: MDPI stays neutral with regard to jurisdictional claims in published maps and institutional affiliations. 